\title{
Spatial Information Systems as Sources of Data for Electromobility Planning
}

\author{
Marcin Staniek \\ Faculty of Transport, Silesian University of Technology \\ Krasińskiego 8 Street, Katowice, Poland \\ marcin.staniek@polsl.pl
}

\begin{abstract}
The article presents spatial information systems as sources of data describing the public space in cities and suburbs. The article focuses on a system used by the local government to manage road infrastructure, including areas designated for car parks. It presents the OSM, a commonly used open data system, which contains data extraction algorithm. The study covered by the article examines existing parking places in the town of Sosnowiec, Poland, as potentially suitable for electric vehicle charging stations. Determination of such convenient locations is one of goals of the international project of Electric Travelling under the ERA-NET CoFund Programme, a project which focuses on developing and implementing a platform supporting electromobility, both from the point of view of transport system users and administrators of transport infrastructure. Moreover, the article presents general objectives of the Electromobility Law and short description of the ETSys platform architecture.
\end{abstract}

Keywords: Electromobility, Availability of data, location of charging station.

\section{Introduction}

Generally, electromobility is the possibility for users to move within a specific transport system while using contemporary newly designed and implemented means of transport with electric engines. The term of electromobility encompasses technical and operational issues, as well as the technology and availability of charging infrastructure. It also involves economic and legal issues related to designing, manufacturing, purchasing and using of electric vehicles with crucial social aspects of transport system user preferences [1]-[4].

The current economic growth in electromobility and social interest result from the policy of sustainable transport development. That policy, according to objectives expressed in the White Paper, should be implemented by all EU member states. Comparing with other EU countries, Poland is at an early stage of the development and implementation of electric propulsion technology. The number of electric vehicles as well as the availability of transport infrastructure is poor. The Electromobility Law adopted on 22.02.2018 [5] includes a number of incentives for those who decide to buy electric, hydrogen and natural gas vehicles. It is designed to promote sales of zero-emission and low-emission vehicles. At the moment, the main obstacle in making such vehicles popular is their high purchase price. The law lifts excise duty on EVs, favourable depreciation solutions for companies, free parking for electric vehicles and the possibility to use bus lanes in cities.

As regards infrastructure, the Electromobility Law [5] defines rules for the development of alternative fuel transport infrastructure, including charging stations for electric cars. A major role regarding electromobility is played by the stimulation of alternative fuel infrastructure as a precondition to encourage people to buy and use electric vehicles. The law defines state administration bodies and local governments as parties required to promote electric vehicles and their use in public transport. Moreover, it defines time framework for the implementation of specific electromobility-related solutions. In combination with the growing interest among companies, the provision of electromobility services bodes well for changes in the previous inefficient and not environmentally friendly approach to the current public transport system [6].

\section{Objectives of the Electric Travelling Project}

To promote the idea of electromobility [7],[8] articulated in the White Paper [9], the Silesian University of Technology, together with their consortium partners, including companies SAITEC and Factor, Spain, universities: Budapest University of Technology and Economics, Hungary, and Delft University of Technology and Over Morgen B.V., the Netherlands, has 
been implementing a research project of 'Electric travelling - platform to support the implementation of electromobility in Smart Cities based on ICT applications'. The main objective of the ET project is to develop tools that support the implementation and development of electromobility in urban and suburban areas. This includes, inter alia, tools for planning of charging stations conveniently located from the point of view of transport system users and the trip planner based on electromobility directly designed to cater the needs of people travelling. The development of the tools should support users while selecting mode of transport, including electric vehicles, and optimised routes, as well as support local governments in determining of directions for the development of electromobility.

The ETSym platform, developed by the project, includes four main modules. Module one, ETPlanner, is used for trip planning since it is based on routing algorithms and it promotes electromobility, e.g. defines locations and availability of charging stations, and takes into account environmental factors to reduce impact on the natural environment. The tool is designed to optimise the everyday travel chain and, while using advanced heuristics approach, it should expand planning and implementation of transport policy objectives in terms of electromobility by local governments. Module two, ETCharge, is crucial from the point of view of the development and availability of infrastructure. While using multi-criteria analysis, the module enables to optimise the deployment of charging stations, and facilitates planning of charging infrastructure in cities by estimating current demand for charging stations and forecasting future requirements. Module three, ETSym, helps to determine relations and limitations for transport system users and simulate various development scenarios for electromobility. The analysis of findings and results is supported by module four - ETReport.

The research area of the ET project on the Polish side is to promote electromobility in the Town of Sosnowiec, Silesia Voivodeship. Fig 1. presents road infrastructure in the town and existing infrastructure for charging of electric vehicles.

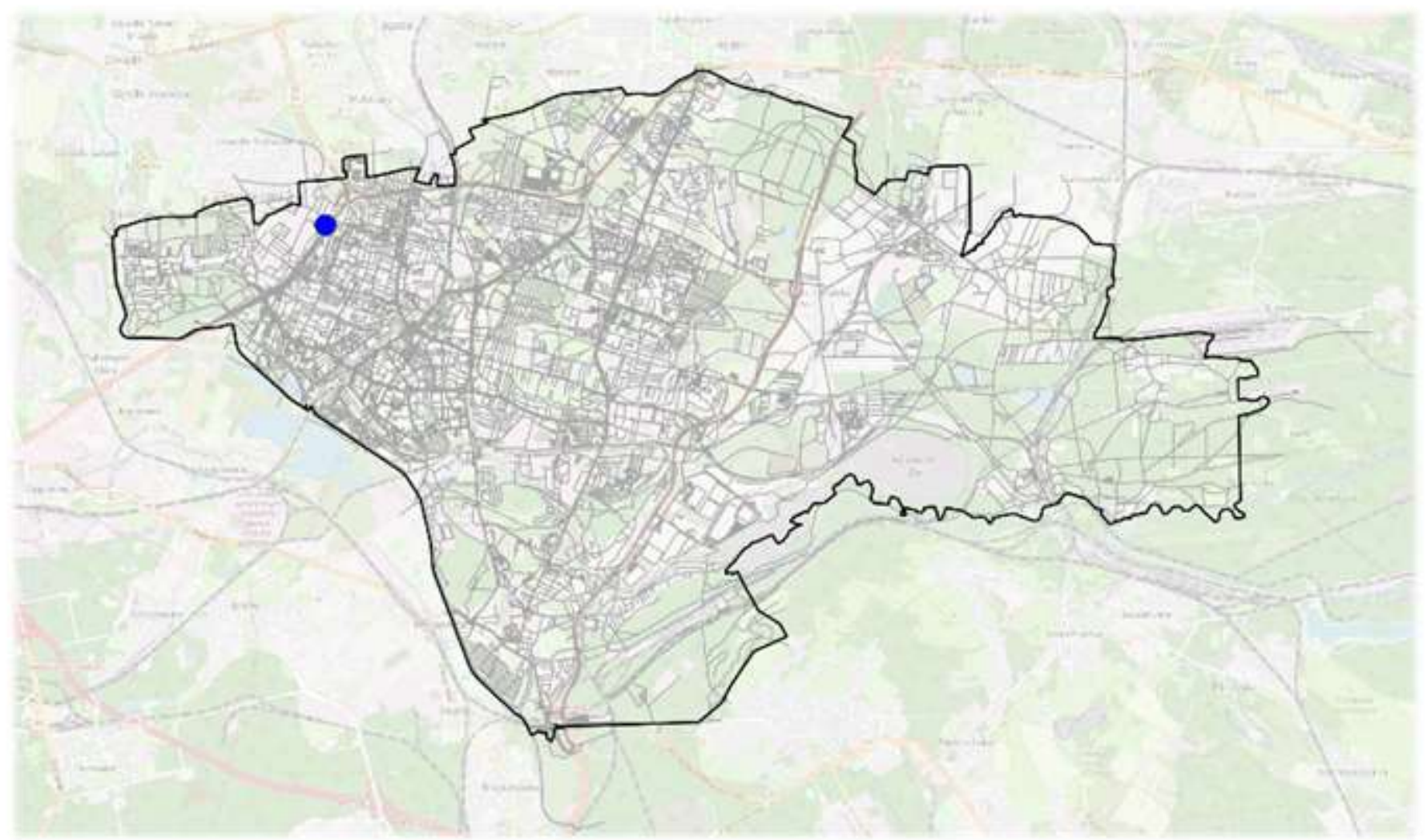

Fig. 1: Town of Sosnowiec, location of charging points for electric vehicles. 
From the point of view of electromobility, the existing charging infrastructure (as of 15.01.2019) in the Town of Sosnowiec is unsatisfactory. Only one charging station is available in the city and no plan has been developed yet to establish new charging stations. The ET project attempted to indicate possible locations for public access charging stations. Commonly available car park space was designated as prospective locations of such installations.

\section{Availability of parking space data}

The identification parking places suitable for charging stations has been based on data from the Integrated Spatial Information System (ZSIP) of the Town of Sosnowiec and data extracted from the database of the Open Street Map (OSM) [10]-[12]. Data concerning parking places included in the Integrated System refer to infrastructure facilities of the following categories: car parks, parking bays and bus bays. Due to a specific designation the last category has been excluded and others are treated as municipal parking space managed by the Town of Sosnowiec. The data set does not include, however, common access car parks at commercial outlets, such as large shops, and car parks at housing estates. The data set comprises 28 car parks of total surface area in excess of 20 thou. sq. $\mathrm{m}$, and 500 parking bays of total area 50 thou. sq. m.

Data pertaining to parking places included in the OSM database have been extracted using plugin quickOSM to arrive at the following query:

( key: amenity - value: "parking") and ( key: city - value: "Sosnowiec")

The query enabled to extract data covering car parks at manufacturing plants, retail and service facilities and public facilities, e.g. stations. Fig. 2 presents locations of parking bays (black) and common access car parks (red), including municipal car parks in the centre of Sosnowiec.

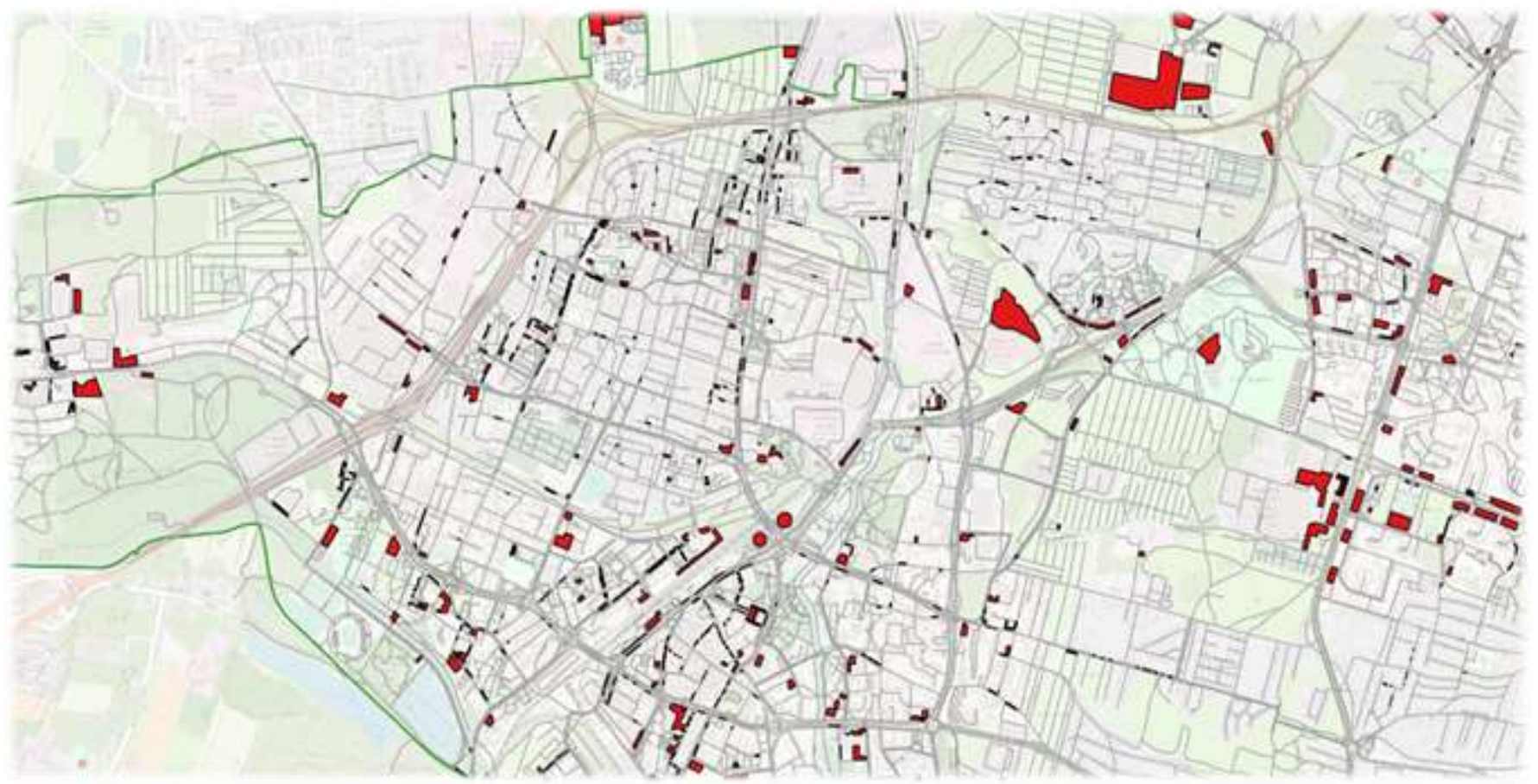

Fig. 2: Possible locations of EV charging points.

Obtained results concerning the parking spaces allow for the unambiguous determination of the possibilities location of charging points. The set consists of over 600 car parks of total area 768 thou. sq. m., however, does not include car parks at housing estates. In addition, the comparison of obtained results with the plans of street lighting infrastructure allows taking potential locations as appropriate for the development of electromobility infrastructure. 


\section{Conclusions}

The inventory of open databases assigned to spatial information systems of the Town of Sosnowiec enables to use data from the Integrated Spatial Information System and OSM. Apart from designating prospective locations for parking space, the target data set helped to identify direct parking space and required data extraction and parameters of those facilities. The total parking space identified using geographic information systems for the Town of Sosnowiec is 850 thou. sq. m. It should be noted, however, that the total area does not include access roads to that parking space. Moreover, the parking space examined excludes private car parks owned by housing cooperatives.

\section{Acknowledgements}

The present research has been financed from the means of the National Centre for Research and Development as a part of the international project within the scope of ERA-NET CoFund Electric Mobility Europe Programme "Electric travelling - platform to support the implementation of electromobility in Smart Cities based on ICT applications".

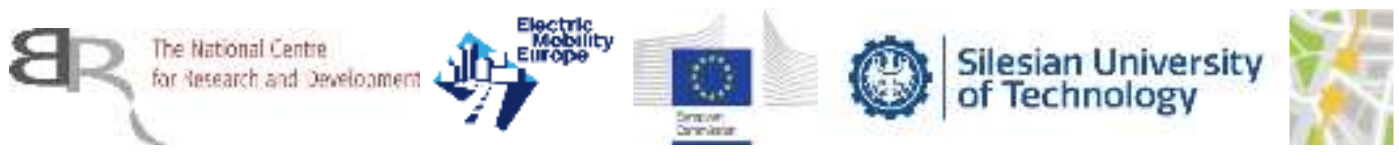

\section{References}

[1] V. Novotny, J. Dobes and D. Hrabal, "Implementing large scale electromobility infrastructure as a profitable virtual electricity storage plant: A case study, system ALISE," in Proceedings of 18th Smart City Symposium Prague (SCSP), Prague, 2018, pp. 1-6.

[2] S. Himmel et al. "Chances for Urban Electromobility," in: Proceedings of International Conference of Design, User Experience, and Usability. Springer, Cham, 2016, pp. 472-484.

[3] H., Quak N. Nesterova, T. Van Rooijen, "Possibilities and barriers for using electric-powered vehicles in city logistics practice," in: Transportation Research Procedia, 2016, vol. 12, pp. 157-169.

[4] Q. Zhao, "Green Innovation Regarding Electromobility in Germany and China: Who and How to Get Involved?" in: Journal of Scientometric Research, 2018, vol. 7, no. 1, pp. 01-08.

[5] Kancelaria Sejmu, "Ustawa o elektromobilności i paliwach alternatywnych", Dz.U.2018 z dn. 11.01.2018 r (in polish).

[6] E. Sendek-Matysiak, "Analysis of the electromobility performance in Poland and proposed incentives for its development," in: Proceedings of XI International Science-Technical Conference Automotive Safety, Casta, 2018, pp. 1-7.

[7] B. Zaunbrecher, Sh. Beul-Leusmann M. Ziefle, "Laypeople's perspectives on electromobility: a focus group study," in: Proceedings of International Internet of Things Summit, Springer, Cham, 2014, p. 144-149.

[8] S. Bitonto, T. Rico, "Electromobility in Germany: Vision 2020 and Beyond," Germany Trade \& Invest, Berlin, 2013.

[9] European Parliament and Council, "Directive 2014/94/EU on the deployment of alternative fuels infrastructure," in: Official Journal of the European Union, 22.10.2014.

[10] I. Celiński, G. Sierpiński, M. Staniek, "Sustainable development of the transport system through rationalization of transport tasks using a specialised travel planner," in: Transport Infrastructure and Systems, G. Dell'Acqua, F. Wegman, Eds. London: CRC Press, Taylor \& Francis Group, 2017, pp. 1071-1079.

[11] G. Sierpiński, M. Staniek, E. Macioszek, "Standardisation of travel planners and use of a return channel," in: Proceedings of the 2nd World Congress on Civil, Structural, and Environmental Engineering, Barcelona, 2017, Paper No. ICTE 121.

[12] E. Macioszek, "First and last mile delivery - problems and issues", in: Advances in Intelligent Systems and Computing, vol. 631, 2018, pp. 147-154. 